\title{
Developing an Indicator System for a Healthy City: Taking an Urban Area as a Pilot
}

This article was published in the following Dove Press journal:

Risk Management and Healthcare Policy

\author{
Tingting $\mathrm{Li}(\mathbb{D})^{1-3}$ \\ Yong Fang 4 \\ Dewei Zeng ${ }^{5}$ \\ Zumin Shi $\mathbb{1 D}^{6}$ \\ Manoj Sharma $\mathbb{D D}^{7-9}$ \\ Huan Zeng ${ }^{1-3}$ \\ Yong Zhao (1D ${ }^{1-3,10}$
}

'School of Public Health and Management, Chongqing Medical University, Chongqing 400016, People's Republic of China; ${ }^{2}$ Research Center for Medicine and Social Development,

Chongqing Medical University, Chongqing 4000 16, People's Republic of China; ${ }^{3}$ The Innovation Center for Social Risk Governance in Health, Chongqing Medical University, Chongqing 400016, People's Republic of China; ${ }^{4}$ Nan'an District Health Center for Woman and Children, Chongqing 400067, People's Republic of China; ${ }^{5}$ Nan'an District Center for Disease Control and Prevention, Chongqing 400067, People's Republic of China; ${ }^{6}$ Human Nutrition Department, College of Health Science, QU Health, Qatar University, Doha, Qatar; ${ }^{7}$ Department of Behavioral and Environmental Health, Jackson State University, Jackson, MS 39213, USA;

${ }^{8}$ Health for All, Omaha, NE 68I24, USA; ${ }^{9}$ Health Sciences, Walden University, Minneapolis, MN 5540I, USA;

${ }^{10}$ Chongqing Key Laboratory of Child Nutrition and Health, Children's Hospital of Chongqing Medical University,

Chongqing 4000I4, People's Republic of China

Correspondence: Yong Zhao; Huan Zeng School of Public Health and Management, Chongqing Medical University, No. I, Medical School Road, Yuzhong District, Chongqing,

People's Republic of China

$\mathrm{Tel}+86-138-8346-0842$

Fax +8602368485008

Email zhaoyong@cqmu.edu.cn;

huanzeng@cqmu.edu.cn

\begin{abstract}
Purpose: The Healthy Cities Project is an important strategy for global health. This study aimed to develop a scientific and appropriate indicator system for the evaluation of a Healthy City in Chongqing, China.
\end{abstract}

Methods: Data were collected via a review of government documents, focus group discussions, and in-depth interviews. A total of 34 government documents were reviewed to build the indicator database based on our previous studies. The first round of focus group discussions, which involved eight health-related experts, was conducted to form the indicator system framework. In-depth interviews with 15 experts from government departments were conducted to design the improved indicator system. The second round of focus group discussions, which featured four experts, was conducted to obtain the final recommended list of indicators. A thematic framework was used to analyze the detailed interview notes.

Results: The indicator system for the Healthy City consisted of 5 first-level indicators, 21 second-level indicators (e.g., health literacy), 73 third-level indicators (e.g., incidence of myopia), and three characteristic indicators. This indicator system spanned the scope of the environment, society, health services, healthy people, and health behaviors.

Conclusion: This indicator system was based on the current status of the construction of the Healthy City in the pilot district. The indicator system could be dynamically adjusted according to the development of the Healthy City in the pilot district. Government departments play an important decision-making role in the development process of this indicator system.

Keywords: healthy city, urban health, indicator system, health in all policy, public health, healthy China

\section{Introduction}

In $2018,55 \%$ of the global population resided in urban areas; by $2050,68 \%$ of the world's population is projected to dwell in urban areas, with nearly $90 \%$ of this growth occurring in Asia and Africa. ${ }^{1}$ Asia accounts for $54 \%$ of the world's urban population, which India, China, and Nigeria combined are expected to account for $35 \%$ of the growth in the world's urban population between 2018 and 2050 . $^{1}$ Meanwhile, the urbanization rate in China increased from $18 \%$ to $56 \%$ from 1978 to 2015, and the trend is expected to continue until $2030 .^{2}$ With China's rapid urbanization, urban health problems have increased, including environmental pollution, the overwhelming burden of noncommunicable diseases, traffic congestion and other side effects. ${ }^{3}$ Actions to promote health have been taken globally to solve these problems.

The Healthy Cities Project was initiated by the World Health Organization (WHO) in the mid-1980s as an approach to deal with urban health by placing 
health high on the political, social, and economic agendas of cities. ${ }^{4,5}$ This project latter expanded into a global movement in a few decades.

The health movement in China started in the 1950s when the country launched the Patriotic Health Campaign, the primary goals of which were to improve sanitary conditions and to control infectious diseases. In 1989, China initiated the Hygienic City project to improve urban environments and advance health management, which was followed by the Hygienic Township in 1997. ${ }^{6}$ The Hygienic City and Hygienic Township were evaluated from eight aspects, with approximately 200 indicators, including the following: health administration, education and promotion, physical outlook, environment quality, sanitation, food and water safety, public health and medical services, and vector control. ${ }^{6,10-13}$ In the 1990s, the country set up a Healthy City pilot project with the collaboration of WHO, and in 2012, the Chinese Ministry of Health proposed "Healthy China" as a national strategy. President Xi Jinping stressed that people's health should be placed high on the agenda, during the National Conference on Health and Wellness, first held in 2016. A new national guideline for health promotion, "Healthy China 2030,"7 was issued in October of that year. And the Evaluation Index System of Healthy City (draft for comment) and the National Evaluation Index System of Healthy City (2018 edition) were published in 2015 and 2018, respectively, ${ }^{14}$ which the latter was divided into 5 first-level indicators, 20 second-level indicators and 42 third-level indicators, spanning five aspects, namely, the environment, society, health services, healthy people, and health culture. In recent decades, the Healthy Cities movement in the country has entered a new stage under the national strategy of "Healthy China."

An appropriate indicator system is a necessary guarantee for the implementation of a Healthy City program. It can describe the health profile of a city, can provide the baseline information for comparison and contracts, and can help the government make proper strategies, interventions, and sustainable health plans. ${ }^{15-19}$ WHO announced ten criteria for a healthy city in 1996, which required a healthy city to provide quality environmental health, harmonious social health and others. The Chinese government has also recommended national indicators for healthy cities. ${ }^{14}$ This research was conducted based on local practice and regarding national recommendations.

In the literature, publications related to urban health indicators have sharply increased in recent years. ${ }^{8,9}$ However, available urban health metrics have focused primarily on large area rankings, and few efforts have been done to develop an index to provide information on the level of health in small geographic areas. ${ }^{18}$ Therefore, the present study intends to develop an indicator system for a Healthy City in a pilot urban area by collecting suggestions from experts who are in charge of Healthy City-related work, and reviewing published literatures and government documents.

\section{Materials and Methods Study Design}

The development of a Healthy City indicator system in the pilot district can promote the development of the Chongqing Healthy City as well as provide an evidence-based reference on the development of a Healthy City indicator system for other cities. Moreover, experience from the development of the European indicator system of urban health suggests that requirements from international organizations and agencies, the availability of data, and policymaking purposes should be all considered. ${ }^{20}$ A review of government documents was performed from October 2017 to November 2017 to build the indicator database. Later, a qualitative study was conducted in the form of focus group discussions and in-depth interviews with experts of senior staff of healthy city-related work from January 2018 to May 2019. The objective was to collect suggestions of including/excluding related indicators.

\section{Data Collection}

\section{Review of Government Documents}

In the previous studies, ${ }^{21,22}$ data were collected through literature review, qualitative interviews, and specialist consultations. The literature on Healthy City indicator systems from three English and three Chinese electronic databases was screened, extracted, and classified. A total of 49 papers were included in the study. Key persons were interviewed in depth regarding the construction of the Healthy City and its evaluation index system. The indicator system for the Chongqing Healthy City which resulted from previous studies was formed after the last two rounds of expert consultations. Such indicator system in previous studies consisted of 8 first-level indicators, 14 second-level indicators, and 103 third-level indicators.

We included documents that primarily focused on issues related to urban health, the National Health City, infectious diseases, and the prevention or control efforts for chronic diseases, etc. based on the previous studies. Several official websites were searched to identify healthrelated policy documents or reports. Examples included 
the national and local web sites of the Ministry of Health, the General Administration of Sport of China, the Food and Drug Administration, Centers for Disease Control and Prevention (CDC), and other relevant websites. The retrieval of government documents was a crucial complement to the preceding literature review. Relevant documents or reports were screened for reading and analysis, and the relevant indicators for the Healthy City were finally extracted. A detailed list of government documents is shown in the Appendix A.

\section{Focus Group Discussions ${ }^{23-25}$}

The first round of focus group discussions was conducted in January 2018. The group consisted of eight solicited experts and opinion leaders from the local Patriotic Health Campaign Committee Office (one man; length of service range: 27 years), the Health Commission (two women; mean length of service: 21 years), CDC (one man; length of service: 15 years), the Education Commission (one man; length of service: 13 years), the Sports Bureau (one man; length of service: 9 years), and other health-related departments (one woman, one man; mean length of service: 20 years). The Patriotic Health Campaign Committee Office is mainly responsible for Healthy City-related affairs in China. The content of this focus group discussion included the framework for a Healthy City indicator system in the pilot district of Chongqing.

On the basis of purposive sampling, two experts from the Chongqing Patriotic Health Campaign Committee Office (two men; mean length of service: 27 years), a senior surgeon and director of the Society of Integrated Traditional Chinese and Western Medicine (one man; length of service: 33 years), and a university professor (one man; length of service: 18 years) who engaged in Healthy City research were invited to participate in the second round of the focus group discussions in May 2019. The content of this focus group discussion was to discuss the problems remaining after the in-depth interviews with multiple departments and the research direction for further study.

The focus group discussions consisted of three steps. In the first step, the moderator, who was in charge of the project, stated the background, purpose, and main issues of the focus group discussion to the recruited participants. In the second step, group members shared their opinions and provided suggestions on the indicator system. Three researchers were present to record the discussions. The third step involved data analysis.

\section{In-Depth Interviews}

A total of 15 participants were included through purposive sampling. In-depth interviews were conducted with section chiefs or senior staff members from the following sectors: Health Commission (two women, one man; length of service range 19-22 years), the Sports Bureau (one man; length of service: 9 years), the Environmental Protection Bureau (one man; length of service: 10 years), the Social Security Bureau (one woman; length of service: 27 years), the Food and Drug Administration(one man; length of service: 28 years), the Civil Affairs Bureau (one woman, one man; mean length of service: 20 years), the Primary and Secondary School Health Care Center (one man; length of service: 13 years), and CDC (three women, two men; length of service range 10-27 years). The interviews were conducted to collect professional feedback from corresponding departments to screen the indicators, with feasibility as a prime consideration.

All the interviews were conducted face-to-face by two interviewers (one acted as the main interviewer, and the other took detailed notes) from October 2018 to January 2019. A detailed preliminary communication was performed to ensure that the interviewees were aware of every detail (objective, content, research method, time, profit, and risk) of the interviews. Each interview lasted 30 to 60 mins and was performed in a private and quiet room. The questions were asked in the local language/ dialect. Advice on the indicator system for a Healthy City was recorded and transcribed.

\section{Data Analysis}

All the recorded interviews or discussions and recordings were first transcribed from the verbatim into Mandarin Chinese by one researcher. Another researcher independently verified the accuracy of the transcript according to the handwritten notes. Then, two researchers reviewed the transcripts repeatedly and highlighted recurring themes. A thematic framework was established after discussions of the research team according to the themes strengthened in the transcripts and interview outline. Later, two researchers with qualitative research experience and were proficient in using the English language conducted data analysis to ensure the good quality of the translated texts. The thematical analysis was used to analyze the detailed interview/discussion notes line-by-line based on grounded theory. ${ }^{26-28}$ The results were presented in aggregate across respondents to protect the identities of the individuals. The 
final list of recommended indicators was formed through a review of government documents, focus group discussions, and in-depth interviews (Figure 1).

\section{Results}

\section{Review of Government Documents}

A total of 34 government documents were reviewed to select related indicators, which comprised the indicator database. The referenced documents were detailed in the "Materials and Methods" section. The indicator database included 6, 23, and 113 indicators at the first, second, and third levels, respectively.

\section{First Round of Focus Group Discussions}

We reached a consensus on the selection of indicators through the focus group discussions. First, the indicators must be uncontroversial and representative, which should be the core indicators in the field. Moreover, the indicators should be set based on the "Healthy China 2030" Plan, the "Healthy Chongqing 2030" Plan, and local health planning. The characteristic indicators should also be customized to suit the local situation, and the rationality of the indicator system should be considered. Advice and suggestions from the discussion are concerned about the following: use of the objective indicators, classification of the indicators, and deletion/supplementation of the indicators. Detailed recommendations are given in the Appendix B.

\section{In-Depth Interviews}

\section{Basic Information from Experts in the in-Depth} Interviews

One of the main findings from the in-depth interviews was the necessity to integrate the efforts of various sectors to improve urban health. This necessity contributed to the extensive subjects of a Healthy City, which involved sectors beyond the environment, health, education, culture, and sports sectors. All of the invited experts had worked in these fields for more than five years. Ultimately, 15 experts participated in face-to-face interviews. The interviewed experts were all beyond the age of 29 years, with an average age of 40.8 years and the oldest being 50 years old. More than $70 \%$ of the participants had been working for over 10 years. The longest length of employment was 32 years, and the average length of employment was 18.4 years (Table 1).

\section{Suggestions of in-Depth Interviews with Multi-Sectors} The main suggestions regarding the indicator system included the following: (1) deleting the indicators with

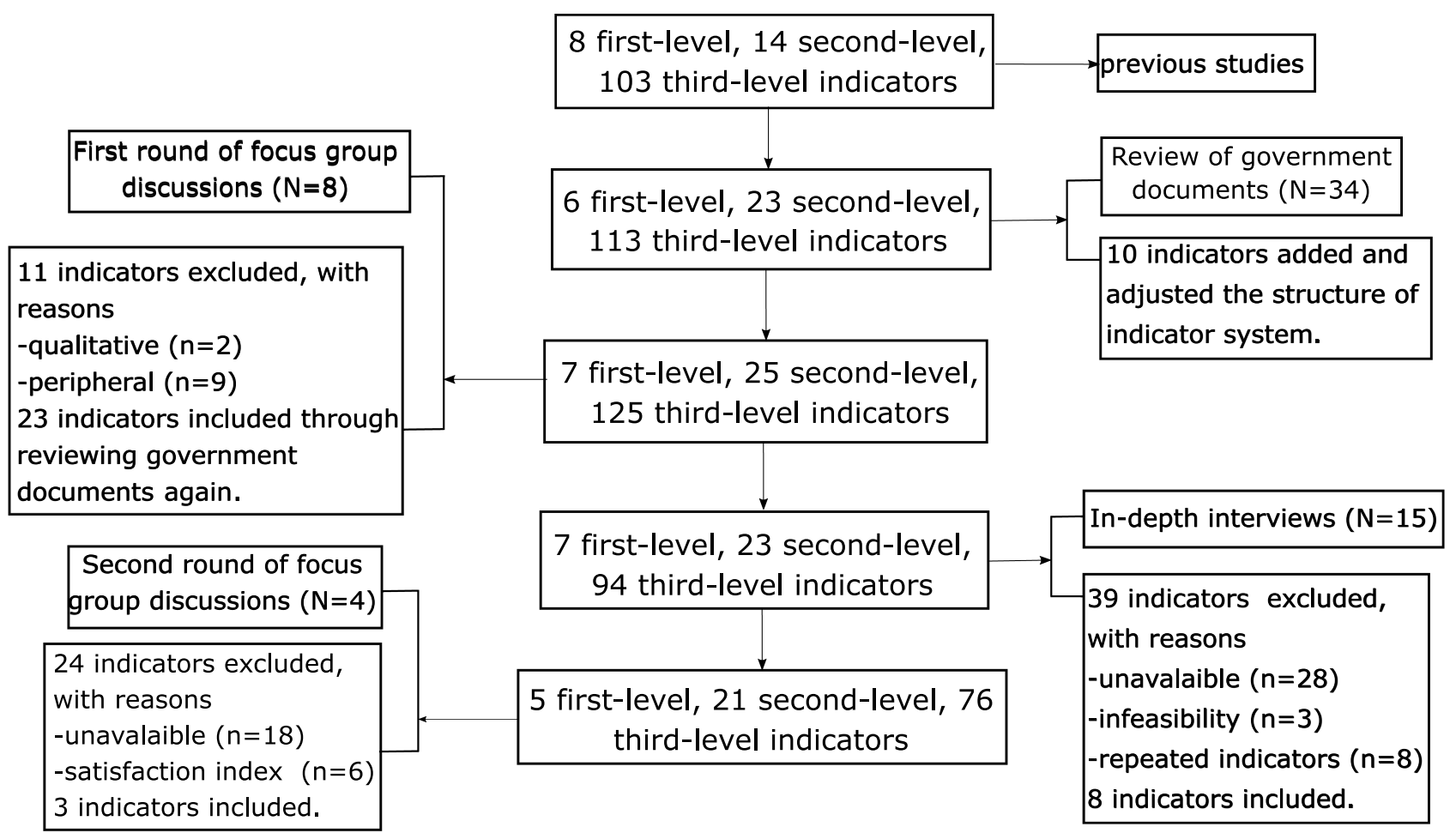

Figure I Flow diagram for the development of the indicator system.

Note: $\mathrm{N}$ number of participants included in focus group discussions or in-depth interviews.

Abbreviation: $n$, number of indicators. 
Table I Demographic Characteristics of in-Depth Interview Participants $(n=15)$

\begin{tabular}{|l|l|}
\hline Variables & N \\
\hline Age (years) & \\
$30-39$ & 7 \\
$40-49$ & 7 \\
$\geq 50$ & 1 \\
\hline Gender & \\
Male & 8 \\
Female & 7 \\
\hline Education & \\
Undergraduate & 10 \\
Graduate & 5 \\
\hline Length of employment (years) & \\
$6-10$ & 4 \\
II-15 & 3 \\
16-20 & 2 \\
$>20$ & 6 \\
\hline
\end{tabular}

low feasibility, (2) ensuring the accuracy of the classification of second-level indicators, and (3) avoiding the selection of similar indicators. (See the Appendix C).

\section{Second Round of Focus Group Discussions}

The experts provided recommendations to omit ambiguous indicators and emphasized three points about the indicator system. First, the selection of the indicators should be based on government documents, such as the "Healthy China 2030" Plan, the "Healthy Chongqing 2030" Plan, and the national statistical yearbook. Second, feasibility and accessibility should be primarily considered in the selection of indicators. Finally, quantitative and outcome indicators should be selected. The experts also advised that two urgent tasks must be done: determining the weight of the indicators at each level and piloting the indicator system to collect data in practical work. See the Appendix D for the detailed suggestions.

The final recommended list included 5 first-level indicators, 21 second-level indicators, 73 third-level indicators, and 3 characteristics indicators, which were all included after the indicator system was revised according to the suggestions of the experts (Table 2). The indicators covered the five aspects, namely, the healthy environment, healthy society, health services, healthy people, and health literacy and health behaviors. Final recommended list of the indicator system for a Healthy City and their definitions are given in the Appendix E.

\section{Discussion}

Our study showed the overall process of the development of an indicator system of a Healthy City in the pilot urban area of Chongqing and concluded with a system featuring 76 indicators. A well-designed indicator system is an important instrument to evaluate the Healthy City program and can help a government find ways to improve urban health. The significance of the study may include: (1) this survey was also a mobilization of Healthy City program; (2) it collected many suggestions and recommendations about Healthy City program; (3) it collected baseline information for evaluating the effect of Healthy City program, with combining the local practice of related departments; (4) it provided evidence-based reference of Healthy City program for other countries. This investigation may have a beneficial role in the decision-making in the implementation and developmental process of a Healthy City with the application of this indicator system.

The number of Healthy City indicators included in the present study (76 indicators) was more than the number of indicators in the European Urban Health Indicators System Project Part 1 (EURO-URHIS 1) consisting of 39 indicators. ${ }^{29}$ The final recommended list of the EUROURHIS 1 included numerous population-related indicators (e.g., population by gender and age, birth rate, life expectancy, prevalence/incidence of illnesses) and involved food and drug-related and environmental indicators. However, environmental indicators, such as road traffic injures, workplace injuries, public access to green space, PM10 exposure, and noise nuisance, were few. The indicator system in the present study encompasses a broad scope, including the environment, population, society, health behavior, health services, and characteristic indicators based on the local context. In addition, the two approaches for developing an indicator system differed. Specifically, the development of the EURO-URHIS involved quantitative (questionnaire) and qualitative (semi-structured interviews) research and investigated how data were used to inform decisions on urban health. In comparison, the present study only conducted qualitative research, namely, focus group discussions and semi-conducted interviews, to develop the indicator system.

In terms of the content of the EURO-URHIS and our indicator system, many similarities and differences exist. On one hand, many common indicators are included in both indicator system, such as birth rate, unemployment rate, low birth weight rate, and partial prevalence of any 
Table 2 Final Recommended List of Indicator System

\begin{tabular}{|c|c|c|}
\hline $\begin{array}{l}\text { First-Level } \\
\text { Indicators }\end{array}$ & $\begin{array}{l}\text { Second-Level } \\
\text { Indicators }\end{array}$ & Third-Level Indicators \\
\hline \multirow[t]{4}{*}{ Healthy environment } & Air quality & $\begin{array}{l}\text { Proportion of days with good and excellent air quality (\%) } \\
\text { PM2.5 concentration }\left(\mu \mathrm{g} / \mathrm{m}^{3}\right)\end{array}$ \\
\hline & Water quality & $\begin{array}{l}\text { Centralized treatment rate of sewage (\%) } \\
\text { Eligibility rate of drinking water quality (\%) } \\
\text { Qualified rate of water quality in centralized drinking water } \\
\text { sources (\%) }\end{array}$ \\
\hline & Waste disposal & Harmless disposal rate of household refuse (\%) \\
\hline & Additional environment & $\begin{array}{l}\text { Per capita park greenbelt area }\left(\mathrm{m}^{2} / \text { person) }\right. \\
\left.\text { Density of Public toilet (seats } / \mathrm{km}^{2}\right) \\
\text { Regional ambient noise (daytime/nighttime) (dB) } \\
\text { Urban road lighting rate (\%) } \\
\text { Green coverage rate in built-up areas (\%) } \\
\text { Vector density control level (\%) }\end{array}$ \\
\hline \multirow[t]{7}{*}{ Healthy society } & Social security & $\begin{array}{l}\text { Coverage rate of basic endowment insurance (\%) } \\
\text { Rate of medical insurance participation (\%) } \\
\text { Civil medical assistance for the minimum living security } \\
\text { crowd } \\
\text { Employment rate of the disabled (\%) } \\
\text { Registered unemployment rate (\%) } \\
\text { Coverage rate of accessibility facilities (\%) }\end{array}$ \\
\hline & Physical activity & $\begin{array}{l}\text { Sports ground area per capita ( } \mathrm{m}^{2} / \text { person) } \\
\text { Number of mass sports instructors per thousand people }\end{array}$ \\
\hline & Industrial safety & $\begin{array}{l}\text { Coverage rate of occupational health examination (\%) } \\
\text { Occupational health monitoring rate of specially supervised } \\
\text { enterprises (\%) } \\
\text { Mortality of production safety accidents per } 100 \text { million GDP } \\
\text { No major occupational disease hazards accidents and laboratory } \\
\text { biosafety accidents in the past } 3 \text { years }\end{array}$ \\
\hline & Safety of food and drug & $\begin{array}{l}\text { Food sampling inspection in four batches/a thousand people } \\
\text { No major food or drug safety accidents in the past } 3 \text { years } \\
\text { Passing rate of medical apparatus sampling inspection (\%) } \\
\text { Passing rate of drug evaluative sampling inspection (\%) } \\
\text { Health certificate coverage rate of ready-to-eat foods } \\
\text { practitioners (\%) }\end{array}$ \\
\hline & Education & $\begin{array}{l}\text { Qualified rate of National student physical health standard (\%) } \\
\text { Incidence of myopia (primary school/junior high school/high } \\
\text { school) (\%) } \\
\text { Offering rate of health education course (compulsory education } \\
\text { only) (\%) }\end{array}$ \\
\hline & Old-age care & Number of old-age beds per 1000 elderly people \\
\hline & Public transportation and housing & $\begin{array}{l}\text { Public transport mode share }(\%) \\
\text { Traffic accident rate per } 10,000 \text { vehicles } \\
\text { Traffic injury mortality }(\%) \\
\text { Per capita housing area }\left(\mathrm{m}^{2} / \text { person) }\right.\end{array}$ \\
\hline
\end{tabular}

(Continued) 
Table 2 (Continued).

\begin{tabular}{|c|c|c|}
\hline $\begin{array}{l}\text { First-Level } \\
\text { Indicators }\end{array}$ & $\begin{array}{l}\text { Second-Level } \\
\text { Indicators }\end{array}$ & Third-Level Indicators \\
\hline \multirow[t]{5}{*}{ Health services } & Health resources & $\begin{array}{l}\text { Number of general practitioners (person/10,000 people) } \\
\text { Number of public health personnel (person/10,000 people) } \\
\text { Number of registered nurses (person/10,000 people) } \\
\text { Number of Psychiatric Practitioners (assistant) (person/100,000 } \\
\text { people) } \\
\text { Number of hospital beds in public traditional Chinese medicine } \\
\text { hospitals (pieces/1000 people) } \\
\text { Number of beds in medical institutions per thousand population } \\
\text { (pieces//000 people) } \\
\text { Health expenditure accounting for the proportion of fiscal } \\
\text { expenditure (\%) } \\
\text { The scale of the health service industry (trillion RMB) }\end{array}$ \\
\hline & Health Records management service & Filing rate of standardized Electronic Health Records (\%) \\
\hline & Key population health services & $\begin{array}{l}\text { Systematic management rate of children (\%) } \\
\text { Systematic management rate of pregnant and parturient women (\%) } \\
\text { Health management rate of the elderly over } 65 \text { years old (\%) } \\
\text { Coverage rate of key population contract services (\%) }\end{array}$ \\
\hline & $\begin{array}{l}\text { Disease management and vaccination } \\
\text { services }\end{array}$ & $\begin{array}{l}\text { Normative management rate of glycemic control (\%) } \\
\text { Normative management rate of blood pressure control (\%) } \\
\text { Management rate of HIV-infected individuals/AIDS patients (\%) } \\
\text { On-site standard treatment rate for sudden acute infectious diseases } \\
\text { (\%) } \\
\text { Normative management rate of tuberculosis patients (\%) } \\
\text { Inoculation rate of immunization planning target population (\%) }\end{array}$ \\
\hline & Mental health management service & $\begin{array}{l}\text { Standard management rate for patients with severe mental } \\
\text { disorders (\%) }\end{array}$ \\
\hline \multirow[t]{3}{*}{ Healthy people } & Health status & $\begin{array}{l}\text { Life expectancy } \\
\text { Mortality of pregnant woman and parturient }(1 / / 00,000) \\
\text { Infant mortality }(\% \circ) \\
\text { Mortality of children under } 5 \text { years old }(\%) \\
\text { Incidence of birth defect }(\%) \\
\text { Low birth weight rate }(\%)\end{array}$ \\
\hline & Infectious disease & $\begin{array}{l}\text { Reported incidence of notifiable infectious diseases }(1 / 100,000) \\
\text { Incidence of tuberculosis }(\%)\end{array}$ \\
\hline & Noncommunicable chronic disease & $\begin{array}{l}\text { Premature mortality of main noncommunicable diseases (\%) } \\
\text { Prevalence of hypertension in adults (\%) } \\
\text { Trends in the incidence of tumor } \\
\text { Trends in the incidence of Cardio-cerebral Vascular Events } \\
\text { Prevalence of obesity (adults/children) (\%) }\end{array}$ \\
\hline \multirow{2}{*}{$\begin{array}{l}\text { Health literacy and health } \\
\text { behaviors }\end{array}$} & Health literacy & Health literacy level (\%) \\
\hline & Healthy behavior & $\begin{array}{l}\text { Smoking rate (by gender) }(\%) \\
\text { Proportion of people who regularly participate in physical exercise (\%) }\end{array}$ \\
\hline Characteristic indicators & & $\begin{array}{l}\text { Number of large-scale (national and above) national fitness activities } \\
\text { held each year } \\
\text { Health science popularization } \\
\text { Construction of health venues }\end{array}$ \\
\hline
\end{tabular}


chronic illness. On the other hand, many other international indicators that reflect the global health concern, such as other important diseases, mental health, and urbanization indicators, and indicators for responding to immigration issues, were not included in our present study. Many international indicators would be gradually established with the efforts of all countries in the world as the development of the Healthy City movement and globalization. Moreover, certain indicators included in our study, which reflected serious urban health issues in China, may gradually become international indicators. China is the largest developing country in the world. Hence, our exploration may contribute to the world Healthy Cities project and the construction of Healthy China, and it also could be beneficial to the promotion and development of Healthy Cities movement in Asian, African and Latin American countries. This topic should be included in our further study.

We found that intersectoral participation is very important for the construction of a Healthy City - a finding that is in accordance with other studies. ${ }^{30,31}$ However, we observed in this study that several senior staff members from government departments lacked a deeper understanding of a Healthy City and confused Healthy Cities with China's Hygienic City. Actually, differences exist between these two types of urban construction activities. The biggest difference is that a Hygienic City has a formal appraisal and naming, whereas a Healthy City does not. From this point, we suggested that government departments should have a staff training program to improve their knowledge of what comprises a Healthy City. In addition, an outstanding difference exists between China's Healthy City and the Healthy Cities Project advocated by the WHO: the Healthy Cities Project, which was promoted by the WHO is an NGO-led urban construction movement, whereas China's Healthy City project is a government-led urban construction project. Therefore, China's Healthy City may have stronger impetus compared with the Healthy Cities Project supported by the WHO.

Our indicator system also revealed new public health issues that emerged in China in recent years. One problem is the severe myopia of Chinese children and adolescents. The results of the National Child and Adolescent Myopia Survey in 2018 showed that the overall prevalence rate of myopia among children and adolescents nationwide was $53.6 \%$. These adolescents consisted of 6-year-old children (14.5\%), primary school students (36.0\%), junior high school students $(71.6 \%)$, and senior high school students $(81.0 \%))^{32}$ The prevalence rate of myopia in primary school students in mainland China is significantly higher than in Western countries. ${ }^{33}$ Other studies showed that the increase in the prevalence rate of myopia was higher among adolescents than in other age groups. ${ }^{34}$ Moreover, the age of myopia prevalence peak has also become much earlier gradually compared with the past years. ${ }^{32,35}$ Enforcing prevention and control of myopia is arduous given that the problem of myopia in the lower age group is more prominent.

Another issue is the increasingly large proportion of the aging population of China. China is one of the fastest ageing countries, having more people aged 65 years and older than any other country in the world, and the proportion of old people in the total national population is projected to be approximately $25 \%$ by $2050 .{ }^{36}$ However, the prevalence of successful aging is low among elder people in China. ${ }^{37}$ In short, the health care needs for the aged also posed severe challenges to the Chinese health care system. ${ }^{38}$ In the Victoria Declaration, the WHO stated that environmental factors and lifestyle are major determinants of affecting human health, accounting for $17 \%$ and $60 \%$, respectively. Hence, our indicator system not only included many indicators of measuring health among citizens but also focused on public health which emphasizes both the natural environment and the social environment. Considering the impact of noise pollution and fine particulate matter on health, regional ambient noise and PM2.5 concentration were added in this indicator system. The chronic disease is also a serious concern in China, so our indicator system also added some health behavior indicators, like smoking, daily salt intake, and exercise.

Several suggestions were provided for further studies. The Hygienic City is the foundation of China's Healthy City. In other words, China's Healthy City is the upgraded version of the Hygienic City. The contrast of their indicators could be a direction for further study, and we may determine the upgraded aspects through comparison. Furthermore, efforts could be made to determine the weight of the indicators in the system. Finally, the indicator system resulting from the present study should be piloted to collect data for future improvements.

Several limitations should be noted in the present study. We only conducted qualitative research to develop an indicator system and did not conduct quantitative research. Furthermore, the indicator system was not verified for practical work; thus, the system may not be generalizable to other areas.

\section{Conclusions}

The present study displayed an overall process of the development of an indicator system of a Healthy City, 
which considered both decision-making and practical work. The indicator system for a Healthy City consists of 5 first-level indicators (health environment, healthy society, health services, healthy people, and health literacy and health behaviors), 21 second-level indicators (e.g., air quality, education, health resources, and health literacy), 73 third-level indicators (e.g., incidence of myopia, regional ambient noise, and trends in the incidence of cardiocerebral vascular events), and 3 characteristic indicators (large-scale national fitness activities, health science popularization, and construction of health venues). Such a indicator system spans the scope of the environment, society, health services, healthy people, and health behavior. The evaluation of a Healthy City requires to integrate efforts cross various departments and institutions.

\section{Ethics Approval}

Ethics approval was obtained from the Ethics Committee of Chongqing Medical University, China (2017021).

\section{Acknowledgment}

We would like to thank all participants in this study for their time and cooperation. Special thanks to Aihua He, Ken Chen from Chongqing Municipal Health Commission for their valuable advice on this paper.

\section{Author Contributions}

Study design: Y.Z., H.Z., and T.L.; data collection: Y.F., D. W., H.Z. Y.Z., and T.L.; data analysis: T.L., H.Z., and Z.S.; data interpretation: T.L., H.Z., and Z.S.; writing original draft: T.L., H.Z.; manuscript review \& editing: T.L., H.Z., Z.S., and M.S.; project administration: D.W., Y.F., and Y. Z.; All authors made substantial contributions to conception and design, acquisition of data, or analysis and interpretation of data; took part in drafting the article or revising it critically for important intellectual content; gave final approval of the version to be published; and agree to be accountable for all aspects of the work.

\section{Funding}

Funding for this study was supported by cooperation program named 'Developing an Indicator System for a Healthy City' between Center for Disease Control and Prevention of Nan'an District in Chongqing and Chongqing Medical University, and also was supported by Chongqing Municipal Health Commission (project no. 2017MSXM158) of China.

\section{Disclosure}

The authors report no conflicts of interest in this work.

\section{References}

1. United Nations, Department of Economic and Social Affairs, Population Division (2018). World urbanization prospects: the 2018 Revision, Online Edition. Available from: file://C:/Users/ltt/Desktop/ WUP2018-Report.pdf. Accessed December 30, 2017.

2. Chinese National Bureau of Statistics. Annual statistical report of China, 2015. Available from: http://www.stats.gov.cn/tjsj/tjgb/ndtjgb/ index_1.html. Accessed December 30, 2017)..

3. Gong P, Liang S, Carlton EJ, et al. Urbanisation and health in China. Lancet. 2012;379(9818):843-852. doi:10.1016/S0140-6736(11)61878-3

4. Rydin Y, Bleahu A, Davies M, et al. Shaping cities for health: complexity and the planning of urban environments in the 21st century. Lancet. 2012;379(9831):2079-2108. doi:10.1016/S01406736(12)60435-8

5. Leonard J, DUHL. The healthy city: its function and its future. Health Promot Int. 1986;1(1):55-60. doi:10.1093/heapro/1.1.55

6. Xu B, Yang J, Zhang Y, Gong P. Healthy cities in China: a lancet commission. Lancet. 2016;388(10054):1863-1864. doi:10.1016/ S0140-6736(16)31724-X

7. National Health Commission of the People's Republic of China. The national health city standards, 2001. Available from: http://www.nhc. gov.cn/jkj/s5898/200804/dcbc5eee5a824ded94f853b049e38d98. shtml. Accessed December 30, 2017.

8. National Health Commission of the People's Republic of China. The national health city standards, 2005. Available from: http://www.nhc. gov.cn/wjw/gfxwj/201304/5d89095fd7c44ebc87bf07d29d4562ab. shtml. Accessed December 30, 2017.

9. National Health Commission of the People's Republic of China. The national health city standards, 2010. Available from: http://www.nhc. gov.cn/jkj/s5898/201006/00688285103749da9ccd1b16e6eaae71. shtml. Accessed December 30, 2017.

10. National Health Commission of the People's Republic of China. The national health city standards, 2014. Available from: http://www.nhc. gov.cn/jkj/s5898/201405/a8ce63259ee640729671917865467a88. shtml. Accessed December 30, 2017.

11. State Council, People's Republic of China. Guideline of "Healthy China 2030" plan. Available from: www.nhc.gov.cn/guihuaxxs/ s3586s/201610/21d120c917284007ad9c7aa8e9634bb4.shtml. Accessed December 30, 2017.

12. National Health Commission of the People's Republic of China. National evaluation index system of healthy city (2018 Edition), 2018. Available from: http://www.nhc.gov.cn/jkj/s5899/201804/fd8c6a7ef3bd41aa9 c24e978f5c12db4.shtml. Accessed December 30, 2017.

13. Webster P, Sanderson D. Healthy cities indicators-a suitable instrument to measure health? J Urban Health. 2013;90(Suppl 1):52-61. doi:10.1007/s11524-011-9643-9

14. Takano T, Nakamura K. An analysis of health levels and various indicators of urban environments for healthy cities projects. J Epidemiol Community Health. 2001;55(4):263-270. doi:10.1136/jech.55.4.263

15. Patterson L, Heller R, Robinson J, et al. Developing a European urban health indicator system: results of EURO-URHIS 1. Eur $J$ Public Health. 2017;27(suppl_2):4-8. doi:10.1093/eurpub/ckv102

16. Rothenberg R, Weaver SR, Dai D, Stauber C, Prasad A, Kano M. A flexible urban health index for small area disparities. J Urban Health. 2014;91(5):823-835. doi:10.1007/s11524-014-9867-6

17. Verma A, van Ameijden E, Birt CA, et al. Why investigate urban health indicators? Eur J Public Health. 2017;27(suppl_2):1-3. doi:10.1093/eurpub/ckv101

18. Prasad A, Gray CB, Ross A, Kano M. Metrics in urban health: current developments and future prospects. Annu Rev Public Health. 2016;37:113-133. doi:10.1146/annurev-publhealth-032315-021749 
19. Pineo H, Glonti K, Rutter H, Zimmermann N, Wilkinson P, Davies M. Urban health indicator tools of the physical environment: a systematic review. J Urban Health. 2018;95(5):613-646. doi:10.1007/s11524-0180228-8

20. Torun P, Heller RF, Harrison A, Verma A. Can health indicators help policy-makers? Experience from European system of urban health indicators (EURO-URHIS). Eur J Public Health. 2017;27(suppl_2): 14-18. doi:10.1093/eurpub/ckv103

21. Huang WJ, Bai RX, Ping HU. Descriptive systematic review on indicator system of healthy city. Med Philos. 2017;38(2):56-59.

22. Huang WJ Research on construction of Chongqing Healthy city evaluation index system. [Master]. Chongqing Medical University, 2016.

23. Wong LP. Focus group discussion: a tool for health and medical research. Singapore Med J. 2008;49(3):256-260.

24. Krueger RA. Focus Groups: A Practical Guide for Applied Research. Thousand Oaks, CA, US: Sage Publications, Inc; 1988:197-p.

25. Tuckett AG, Stewart DE. Collecting qualitative data: part II. Group discussion as a method: experience, rationale and limitations. Contemp Nurse.2004. 16(3):240-251.

26. Ziebland S, Chapple A, Dumelow C, et al. How the internet affects patients' experience of cancer: a qualitative study. BMJ (Online). 2004;328(7439):564.

27. Chabrol F, Noah Noah D, Tchoumi EP, et al. Screening, diagnosis and care cascade for viral hepatitis B and C in Yaoundé, Cameroon: a qualitative study of patients and health providers coping with uncertainty and unbearable costs. BMJ Open. 2019;9:3. doi:10.1136/bmjopen-2018-025415

28. Adjei CA, Stutterheim SE, Naab F, et al. Chronic Hepatitis B stigma in Ghana: a qualitative study with patients and providers. BMJ Open. 2019;9(6):e025503. doi:10.1136/bmjopen-2018-025503
29. The University of Manchester, Oxford Rd. European Urban Health Indicators System Project Part 1 (EURO-URHIS 1). Available from: http://www.urhis.eu/euro-urhis1/. Accessed December 30, 2017).

30. Kenzer M. Healthy cities: a guide to the literature. Public Health Rep. 2000;115(2-3):279-289. doi:10.1093/phr/115.2.279

31. O'Neill M, Simard P. Choosing indicators to evaluate healthy cities projects: a political task? Health Promot Int. 2006;21(2):145-152. doi:10.1093/heapro/dal006

32. National Health Commission of the People's Republic of China. Press conference. Available from: http://www.nhc.gov.cn/xcs/s7847/201904/ e9117ea8b6b84f48962e84401d305292.shtml. Accessed May 21, 2018.

33. Ding BY, Shih YF, Lin LLK, Hsiao CK, Wang IJ. Myopia among schoolchildren in East Asia and Singapore. Surv Ophthalmol. 2017;62(5):677-697. doi:10.1016/j.survophthal.2017.03.006

34. Xu XQ, Li SP, Xu YJ, Wei J. Prevalence of myopia among primary school students in mainland China: a meta-analysis. Int Eye Sci. 2016;16(7):1221-1227.

35. Dong YH, Liu HB, Wang $\mathrm{ZH}$, et al. Prevalence of myopia and increase trend in children and adolescents aged 7-18 years in Han ethnic group in China, 2005-2014. Chin J Epidemiol. 2017;38 (5):583-587. doi:10.3760/cma.j.issn.0254-6450.2017.05.005

36. Liu H, Byles JE, Xu X, Zhang M, Wu X, Hall JJ. Evaluation of successful aging among older people in China: results from China health and retirement longitudinal study. Geriatr Gerontol Int. 2017;17(8):1183-1190. doi:10.1111/ggi.2017.17.issue-8

37. The Lancet editorial. Ageing in China: a ticking bomb. Lancet. 2016;388(10056):2058. doi:10.1016/S0140-6736(16)32058-X

38. Fang EF, Scheibye-Knudsen M, Jahn HJ, et al. A research agenda for aging in China in the 21st century. Ageing Res Rev. 2015;24(Pt B):197-205. doi:10.1016/j.arr.2015.08.003
Risk Management and Healthcare Policy

\section{Publish your work in this journal}

Risk Management and Healthcare Policy is an international, peerreviewed, open access journal focusing on all aspects of public health, policy, and preventative measures to promote good health and improve morbidity and mortality in the population. The journal welcomes submitted papers covering original research, basic science, clinical \& epidemiological studies, reviews and evaluations, guidelines, expert opinion and commentary, case reports and extended reports. The manuscript management system is completely online and includes a very quick and fair peer-review system, which is all easy to use. Visit http://www.dovepress.com/testimonials.php to read real quotes from published authors. 